\title{
Factors Affecting the Plasmin-Plasminogen System in Milk Obtained from Three Greek Dairy Sheep Breeds with Major Differences in Milk Production Capacity
}

\author{
G. Theodorou, A. Kominakis, E. Rogdakis, and I. Politis ${ }^{1}$ \\ Department of Animal Science, Agricultural University of Athens, 11855 Athens, Greece
}

\begin{abstract}
The purpose of this study was to evaluate the effect of breed, stage of lactation, and health status of the udder on the plasmin-plasminogen system in ovine milk. A total of 38 ewes were used from 3 breeds [Boutsiko $(\mathrm{n}=12)$, Chios $(\mathrm{n}=12)$, and a synthetic breed $(50 \%$ Boutsiko, 25\% Arta, and 25\% Chios, $\mathrm{n}=14$ )] with major differences in their genetic potential with respect to milk yield. Milk samples were collected every $2 \mathrm{wk}$ throughout the lactation period and were analyzed for fat, protein, lactose, and somatic cell count (SCC). In addition, milk plasmin (PL), plasminogen (PG), and plasminogen activator (PA) activities were determined. The Chios breed had the greatest average daily milk yield, the synthetic breed had an intermediate milk yield, and ewes of the Boutsiko breed had the lowest milk yield. Milk samples obtained from the Boutsiko breed had similar PL and PA activities, compared with those obtained from the other 2 breeds. The ratio of PG:PL was less in milk samples from the Boutsiko breed compared with the other 2 breeds, indicative of an increased rate of conversion of PG to PL for this breed. There was no correlation between PL activity and daily milk yield in ewes from all 3 breeds. Activities of PL, PG, and PA were greater in ovine milk with elevated SCC $(>300,000 / \mathrm{mL})$ compared with activities in milk with low $\mathrm{SCC}(<300,000 / \mathrm{mL})$. The ratio of PG:PL was less in the high-SCC group compared with the lowSCC group, which indicates an increased rate of conversion of PG to PL for the high-SCC group. There was a decrease in PG and PA activities as well as in the PG:PL ratio in late lactation milk (mo 5 to 6 ) when compared with early or mid lactation milk (mo 1 to 4 ). Thus, the PL-PG system is affected by breed, stage of lactation, and the health status of the udder. No relationship was found between PL activity and daily milk yield in the
\end{abstract}

Received November 22, 2006.

Accepted March 9, 2007.

${ }^{1}$ Corresponding author: i.politis@aua.gr
3 Greek dairy sheep breeds. Plasmin is not a marker for gradual involution in the Greek sheep breeds studied. Key words: plasmin, plasminogen, plasminogen activator, ovine milk

\section{INTRODUCTION}

Several serine proteinases are present in milk. Plasmin (PL), which occurs in milk together with its inactive zymogen plasminogen (PG), is the most significant protease contributing to total proteolytic activity (Politis et al., 1989; Politis, 1996). Plasmin hydrolyzes $\alpha_{\mathrm{s}^{-}}$ $\mathrm{CN}$ and $\beta$-CN in milk and decreases milk's ability to withstand processing. Increased activities of PL and plasminogen activator (PA) have been associated with a deterioration of the coagulation properties of milk because of proteolysis of CN by PL (Srinivasan and Lucey, 2002).

A number of studies have examined the importance of the PL-PG system in the bovine mammary gland. Politis et al. (1989) provided data indicating that enhanced conversion of PG to PL is correlated with gradual involution (the declining phase of lactation). Plasmin might be a marker for gradual involution. Milk obtained during the first 5 to 6 mo of lactation contains low amounts of PL and PG; plasmin and PG increase in late lactation milk. However, the PG:PL ratio, an index independent of changes in milk volume, declines as lactation advances, indicating enhanced conversion of PG to PL during late lactation. Gilmore et al. (1995) found that late lactation milk contained more PA than did early lactation milk. Stage of lactation also affects the PL-PG system in ovine milk, but the results are inconclusive. Late lactation was associated with higher concentrations of milk PL and PA in Sardinian ewes (Bianchi et al., 2004). On the contrary, Albenzio et al. $(2004,2005)$ reported that the highest activities of PL and PG were observed in early lactation milk and the lowest in late lactation milk obtained from Comisana ewes.

The PL-PG system in ovine milk is affected by the health status of the udder. More specifically, PL and 
PA activities were greater by 74 and $139 \%$, respectively, in infected vs. noninfected glands (Leitner et al., 2004). Furthermore, Bianchi et al. (2004) reported that elevated SCC was associated with increased PL activity (18\%), and decreased PA activity (23\%), whereas PG activity did not vary with SCC. Albenzio et al. (2004) reported increased PL activity for milk samples with high SCC $(>1,000,000 / \mathrm{mL})$ compared with those with low SCC $(<500,000 / \mathrm{mL})$ throughout lactation. Furthermore, there was an increase in PG activity for milk samples with high SCC compared with low SCC only during mid lactation (110 to $130 \mathrm{~d}$ of lactation).

Dairy sheep farming is a sector of major economic importance in Greece. Two typical indigenous breeds, Chios and Boutsiko, along with a synthetic breed were used in this study. The Chios breed is characterized by high milk yield and litter size, whereas the lessproductive Boutsiko breed is known for its adaptability under harsh environmental conditions and its reduced susceptibility to mastitis (Hatziminaoglou et al., 1990; Simos et al., 1996; Kominakis et al., 1998; Ploumi et al., 1998). The synthetic breed (50\% Boutsiko, 25\% Arta, and 25\% Chios) has been recently formed in an attempt to upgrade the Boutsiko breed by combining the high productivity of the Chios and Arta breeds with the robustness of the Boutsiko breed. The PL-PG system has not been investigated extensively in dairy sheep breeds with substantial differences in their genetic potential with respect to milk production.

The objective of the present study was to develop a model describing the PL-PG system in ovine milk. Relationships between several factors (breed, stage of lactation, and health status of the udder) and activities of milk PL, PG, and PA were evaluated. Important relationships were then further assessed as to their causative involvement in the PL-PG system. Moreover, correlations among PL, PG, and PA with all major milk components were determined. The significance (or lack of it) of the PL-PG system for the phenomenon of gradual involution in sheep was examined.

\section{MATERIALS AND METHODS}

\section{Animals and Milk Sampling}

Thirty-eight ewes were used in this study; 12 from the Boutsiko breed, 14 from a synthetic breed (50\% Boutsiko, 25\% Arta and 25\% Chios), and 12 from the Chios breed. Animals were housed within the premises of the experimental farm of the Agricultural University of Athens. The ewes lambed between November 10, 2005 , and January 10, 2006. All ewes that lambed outside of this period, independently of their lambing number, were excluded from the experiment. It was essential that all animals completed their lactations by the first week of July to avoid the extremely hot conditions that occur in Greece during July and August. Ewes of the Boutsiko and the synthetic breeds were in their first lambing, whereas ewes of the Chios breed were in their second or third lambing. After weaning ( $45 \mathrm{~d}$ after lambing), the ewes were milked twice daily at 0500 and $1700 \mathrm{~h}$ using a milking machine. Individual milk yield was recorded every $2 \mathrm{wk}$ and milk samples were collected during the morning and evening milking on the same dates. Milk samples were divided into 2 aliquots; the first was immediately analyzed for major milk components and the second aliquot was frozen and stored at $-20^{\circ} \mathrm{C}$ for PL, PG, and PA analysis. Samples were collected for 6 mo after weaning (entire lactation).

Milk samples were analyzed for fat, protein, and lactose by the infrared method using a Milkoscan 133 (Foss Electric, Hillerød, Denmark) calibrated against the Mojonnier method for fat, Kjeldahl method for protein, and the polarimetric method for lactose according to official methods (AOAC, 1980). Somatic cell count was determined with a Fossomatic cell counter (Foss Electric).

\section{Determination of PL, PG, and PA Activities}

Activities of PL and PG (also called plasminogenderived activity) in milk were determined by a combination of the methods described by Politis et al. (1989) and Politis and Ng Kwai Hang, 1989). In detail, milk (3 mL) was mixed with $1 \mathrm{~mL}$ of $0.4 M$ sodium citrate and centrifuged at $27,000 \times g$ for $20 \mathrm{~min}$. The supernatant was recovered and assayed for PL and PG. Plasminogen-derived activity is defined as the PL activity generated after addition of urokinase. The sum of PL+PG was calculated by adding the activity of PL plus the activity of PG. Both assays were performed in 250 $\mu \mathrm{L}$ of $0.1 M$ Tris-HCl buffer ( $\mathrm{pH} 7.4$ ) containing $0.6 \mathrm{mM}$ Val-Leu-Lys-p-nitroanilide (V7127; Sigma Chemical Co., St Louis, MO), 30 Plough units $(2.5 \mu \mathrm{L})$ of urokinase (U0633; Sigma), and $30 \mu \mathrm{L}$ of the milk supernatant. All assays were duplicated. The reaction mixture was incubated at $37^{\circ} \mathrm{C}$ and absorbance at $405 \mathrm{~nm}$ was recorded at hourly intervals. A sample without supernatant served as a control for the detection of spontaneous breakdown of the substrate. In all cases, spontaneous hydrolysis was negligible. Plasmin activity was measured in the same reaction mixture without added urokinase. Plasmin and PG activities were determined from the linear part of the absorbance vs. time curve. One unit of PL was defined as the amount of enzyme that produced a change in absorbance of 0.1 at $405 \mathrm{~nm}$ in $60 \mathrm{~min}$.

A colorimetric assay was used to measure PA activity in the CN fraction (Gilmore et al., 1995). The principle of 

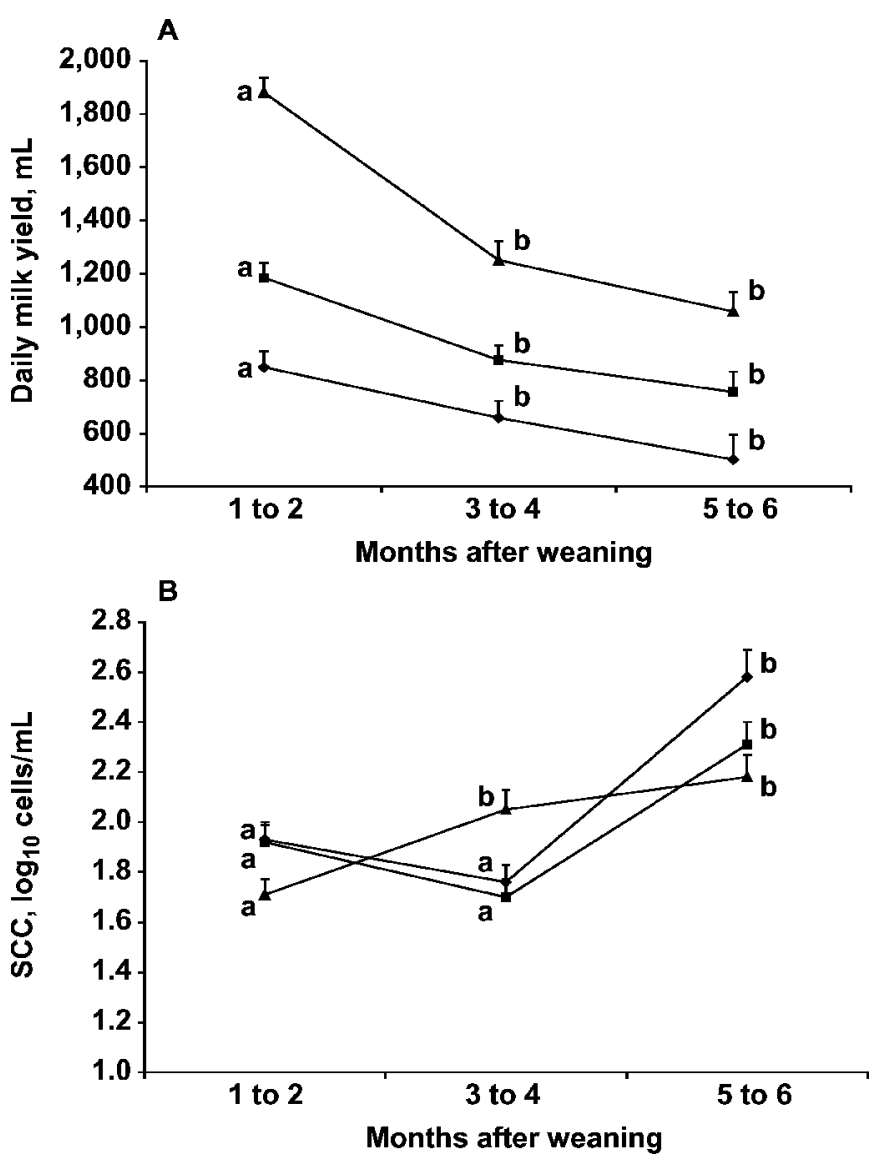

Figure 1. Effect of stage of lactation on (A) daily milk yield and (B) SCC for the 3 Greek dairy sheep breeds: Boutsiko ( ), synthetic $(\boldsymbol{\square})$, and Chios $(\mathbf{\Delta}){ }^{\mathrm{a}, \mathrm{b}}$ Means within the same breed with different letters differ at $P<0.05$.

this methodology is that PA in the $\mathrm{CN}$ fraction converts exogenously supplied PG to PL. The PL hydrolyzes the chromogenic substrate, Val-Leu-Lys-p-nitroanilide, liberating the chromophore, p-nitroaniline. Changes in color were directly related to PL level and therefore indirectly to PA activity. Details of this method are outlined by Gilmore et al. (1995).

\section{Statistical Analysis}

Significant departures from normal distribution (ND) for all variables and possible outliers were initially assessed using the quantile-quartile (Q-Q) plots. The plots revealed curvature at the long tails, implying outliers for the 3 variables (PL, PG, and PA). Calculation of the extreme studentized deviates (ESD) for the above variables was used according to Grubbs (1969) and outliers were excluded at a 2-tailed probability of 0.05 . More specifically, values per variable were excluded for $\mathrm{PL}$ (530, ESD = 13.27, $P<0.0001 ; 203, \mathrm{ESD}=$
4.67, $P=0.0017)$, PG $(300, \mathrm{ESD}=5.48, P<0.0001)$, and $\mathrm{PA}(938, \mathrm{ESD}=8.19, P<0.0001 ; 538, \mathrm{ESD}=3.97$, $P=0.0336$ ). The square root for PL, PG, and PA, and logarithmic transformation for SCC values were then used in an attempt to meet ANOVA assumptions (i.e., normal distribution and homogeneity of variance within class effects). Transformed values of variables were then analyzed using a linear mixed model appropriate for repeated measurements per subject (animal) with the autoregressive order one [AR(1)] for modeling the error covariance structure. The fixed effects in the model included the effects of breed (3 levels: Chios, Boutsiko, and synthetic), lactation stage (3 levels: early, 1 to $2 \mathrm{mo}$; mid, 3 to $4 \mathrm{mo}$; and late, 5 to $6 \mathrm{mo}$ ), and level of SCC (2 levels: above and below 300,000 cells $/ \mathrm{mL}$ ). All the interaction terms were included in the model. They were found nonsignificant and were, therefore, omitted from the model. The effect of animal nested within breed was fitted as a random effect. The high SCC samples were distributed into 14 samples in early lactation, 15 samples in mid lactation, and 24 samples in late lactation. Lactation was confounded with season and this confounding created a possible overlapping effect. The confounding, however, occurred in all animals moving in a synchronous manner through lactation. The Satterthwaite method was used for computing the denominator degrees of freedom for the tests of fixed effects and a Tukey-Kramer adjustment for the $P$-values because multiple comparisons were used. Results of mixed ANOVA are presented as least squares means with standard errors. All mixed ANOVA analyses were carried out by PROC MIXED (SAS Institute, 2004). For the ratio variable PG:PL that clearly deviated from ND before and after any transformation was applied, the Kruskal-Wallis nonparametric test was used. The Kruskal-Wallis nonparametric test identified significant class effect (breed, lactation stage, or level of SCC) differences when the number of classes was greater than 2 . When a significant difference between medians was established, a Wilcoxon-Mann-Whitney test was used to detect pairwise statistically significant median differences. Results of these nonparametric test(s) are presented as medians with interquartile ranges (Q3-Q1). Partial correlations between the variables PL, PG, PA, SCC, daily milk yield, and fat, protein, and lactose concentrations were obtained from the error (residual) matrix of the dependent variables after fitting a multivariate ANOVA (MANOVA); the MANOVA was performed by PROC GLM (SAS Institute, 2004).

\section{RESULTS}

The effect of breed on the major milk components is presented in Table 1. The Chios breed had lower fat, 
Table 1. Least squares means ( $₫$ SEM) of major milk components for 3 breeds of Greek dairy sheep

\begin{tabular}{lccc}
\hline & \multicolumn{3}{c}{ Breed } \\
\cline { 2 - 4 } Item & Boutsiko & Synthetic & Chios \\
\hline Observations, $\mathrm{n}$ & 112 & 146 & 124 \\
Fat, \% & $7.07 \pm 0.14^{\mathrm{a}}$ & $6.39 \pm 0.12^{\mathrm{b}}$ & $6.14 \pm 0.12^{\mathrm{b}}$ \\
Protein, \% & $5.85 \pm 0.05^{\mathrm{a}}$ & $5.74 \pm 0.04^{\mathrm{a}}$ & $5.49 \pm 0.05^{\mathrm{b}}$ \\
Lactose, \% & $4.77 \pm 0.03^{\mathrm{a}}$ & $4.72 \pm 0.02^{\mathrm{a}}$ & $4.61 \pm 0.02^{\mathrm{b}}$ \\
\hline
\end{tabular}

${ }^{\mathrm{a}, \mathrm{b}}$ Means within the same row followed by different letters differ at $P<0.05$.

protein, and lactose concentrations compared with the other 2 breeds. Daily milk yield and SCC for all 3 breeds at different stages of lactation are presented in Figure 1. The highest milk yield was recorded in early lactation (1 to 2 mo after weaning) and declined thereafter (Figure 1A). The Chios breed had the greatest daily milk yield, the synthetic breed had an intermediate daily milk yield, and the Boutsiko breed had the lowest daily milk yield. The greatest SCC was recorded in late lactation and the lowest SCC was recorded in early or mid lactation (Figure 1B). There were no consistent differences in SCC between the 3 breeds across the entire lactation. The Chios breed had lower SCC at early lactation but greater SCC at mid lactation compared with the other 2 breeds.

The effect of breed on PL, PG, and PA activities, the PG:PL ratio, and the sum of $\mathrm{PL}+\mathrm{PG}$ are presented in Table 2. There were no differences in PL and PA activities between the 3 breeds. Plasminogen activity and the PG:PL ratio were lower in the Boutsiko breed compared with the other 2 breeds. The sum of PL+PG was lower in the Boutsiko breed compared with the Chios breed.

The effect of stage of lactation on PL, PG, and PA activities, the PG:PL ratio, and the sum of $\mathrm{PL}+\mathrm{PG}$ is presented in Table 3. There were no differences in PL, PG, and PA activities, the PG:PL ratio, and the sum of
PL+PG between early (1 to 2 mo) and mid lactation (3 to $4 \mathrm{mo}$ ) milk. Late lactation (5 to $6 \mathrm{mo}$ ) milk was associated with lower PG and PA activities compared with early and mid lactation milk. Furthermore, the PG:PL ratio was lower in late lactation milk compared with early and mid lactation milk. The change in PG:PL ratio indicates accelerated conversion of $\mathrm{PG}$ to $\mathrm{PL}$ during late lactation. The sum of PG +PL was less in late lactation milk compared with early and mid lactation milk.

The effect of the mammary health status (SCC) on PL, PG, and PA activities, the PG:PL ratio, and the sum of PL+PG is presented in Table 4. The high SCC $(>300,000$ cells $/ \mathrm{mL}$ ) milk had greater PL, PG, and PA activities when compared with the low SSC $(<300,000$ cells $/ \mathrm{mL}$ ) milk. The PG:PL ratio was less and the sum of PG+PL was greater in the high-SCC compared with the low-SCC milk.

Partial correlation coefficients between PL, PG, and PA activities and milk yield were calculated. The correlations between PL, PG, and PA activities and daily milk yield were not significant when breed was either included or omitted from the model.

\section{DISCUSSION}

The first finding emerging from the present study was that PL and PA activities were similar for the 3

Table 2. Least squares means ( \pm SEM) of plasmin (PL), plasminogen (PG), plasminogen activator (PA), and the sum of PL+PG activities along with the medians and the interquartile ranges of the PG:PL ratio for 3 breeds of Greek dairy sheep ${ }^{1}$

\begin{tabular}{lccc}
\hline & \multicolumn{3}{c}{ Breed } \\
\cline { 2 - 4 } Item & Boutsiko & Synthetic & Chios \\
\hline Observations, $\mathrm{n}$ & 112 & 144 & 123 \\
$\mathrm{PL}, \mathrm{U} / \mathrm{mL}{ }^{2}$ & $6.70 \pm 0.29$ & $7.00 \pm 0.26$ & $7.30 \pm 0.26$ \\
$\mathrm{PG}, \mathrm{U} / \mathrm{mL}$ & $6.02 \pm 0.33^{\mathrm{a}}$ & $7.09 \pm 0.29^{\mathrm{b}}$ & $7.52 \pm 0.30^{\mathrm{b}}$ \\
$\mathrm{PA}, \mathrm{U} / \mathrm{mL}$ & $10.57 \pm 0.42$ & $11.54 \pm 0.38$ & $11.62 \pm 0.39$ \\
PL+PG, U/mL & $9.17 \pm 0.39^{\mathrm{a}}$ & $10.16 \pm 0.35^{\mathrm{ab}}$ & $10.67 \pm 0.36^{\mathrm{b}}$ \\
PG:PL ratio & & & $1.75^{\mathrm{b}}$ \\
Median & $0.98^{\mathrm{a}}$ & $1.38^{\mathrm{b}}$ & 1.32 \\
Interquartile range & 0.43 & 1.18 & \\
\hline
\end{tabular}

${ }^{\mathrm{a}, \mathrm{b}}$ Means within the same row followed by different letters differ at $P<0.05$.

${ }^{1}$ All values are from the main effects fitted in the model and they are square-root transformed.

${ }^{2} \mathrm{U}=$ activity unit; 1 unit is the amount of PL that produces a change in absorbance of 0.1 at $405 \mathrm{~nm}$ in $60 \mathrm{~min}$. 
Table 3. Least squares means $( \pm \mathrm{SEM})$ of plasmin $(\mathrm{PL})$, plasminogen $(\mathrm{PG})$, plasminogen activator (PA), and the sum of PL+PG activities along with the medians and the interquartile ranges of the PG:PL ratio by stage of lactation ${ }^{1}$

\begin{tabular}{lccc}
\hline & \multicolumn{3}{c}{ Months after weaning } \\
\cline { 2 - 4 } Item & 1 to 2 & 3 to 4 & 5 to 6 \\
\hline Observations, $\mathrm{n}$ & 159 & 137 & 83 \\
PL, U/mL & $7.16 \pm 0.26$ & $7.30 \pm 0.28$ & $6.53 \pm 0.29$ \\
PG, U/mL & $7.25 \pm 0.30^{\mathrm{a}}$ & $7.31 \pm 0.31^{\mathrm{a}}$ & $6.07 \pm 0.33^{\mathrm{b}}$ \\
$\mathrm{PA}, \mathrm{U} / \mathrm{mL}$ & $12.79 \pm 0.39^{\mathrm{a}}$ & $12.36 \pm 0.41^{\mathrm{a}}$ & $8.58 \pm 0.43^{\mathrm{b}}$ \\
PL+PG, U/mL & $10.53 \pm 0.36^{\mathrm{a}}$ & $10.50 \pm 0.38^{\mathrm{a}}$ & $8.97 \pm 0.39^{\mathrm{b}}$ \\
PG:PL ratio & $1.43^{\mathrm{a}}$ & & \\
Median & 1.40 & $1.67^{\mathrm{a}}$ & $0.91^{\mathrm{b}}$ \\
Interquartile range & 1.24 & 0.37 \\
\hline
\end{tabular}

${ }^{\mathrm{a}, \mathrm{b}}$ Means within the same row followed by different letters differ at $P<0.05$.

${ }^{1}$ All values are from the main effects fitted in the model and they are square-root transformed.

${ }^{2} \mathrm{U}=$ activity unit; 1 unit is the amount of PL that produces a change in absorbance of 0.1 at $405 \mathrm{~nm}$ in $60 \mathrm{~min}$.

dairy sheep breeds. The PG:PL ratio is a useful index of PG activation and more importantly a measurement independent of milk volume. Interestingly, differences were detected in the PG:PL ratio between the 3 breeds. The PG:PL ratio was lower in the Boutsiko breed compared with the other 2 breeds. The PG occurs, therefore, in equal or moderately greater amounts than PL in ovine milk obtained from the 3 breeds. Accelerated conversion of PG to PL occurs in the Boutsiko breed.

Differences between the Chios breed compared with the other 2 breeds could be attributed to differences in their lambing number (first lambing vs. second and third lambings). Unpublished data from our laboratory, however, indicate that there are no differences in PL, PG, and PA activities for the first 4 lambings. Furthermore, Politis and Ng Kwai Hang (1989) reported that PL activity in bovine milk did not differ between the first 3 lactations. Moreover, Politis et al. (1989) reported that lactation number did not affect PL and PG activities in bovine milk.

The data for the PG:PL ratio in ovine milk obtained from the 3 Greek dairy sheep breeds are similar to those of Bianchi et al. (2004) who reported that the PG:PL ratio ranged between 1.08 and 2.40 in multiparous Sardinian ewes. Albenzio et al. (2004) found that the PG:PL ratio was less than 1 in the majority of cases studied (except mid lactation milk). Greater values for the PG:PL ratio (3.45) were reported for uninfected glands in milk from Assaf dairy sheep (Leitner et al., 2004). In bovine milk, the majority of the enzyme is in its inactive form (PG). Politis et al. (1990) found that the PG:PL ratio ranged between 6.3 (early lactation milk) and 3.6 (late lactation milk). Baldi et al. (1996), who investigated the PG:PL ratio in bovine milk obtained from 4 Italian dairy herds, reported that the PG:PL ratio was between 2.4 and 6 . Two New Zealand studies reported that the PG:PL ratio in late lactation bovine milk ranged between 31.29 and 81.2 , suggesting that PL was extremely low in New Zealand milk (Stelwagen et al., 1994; Lacy-Hulbert et al., 1999). The data concerning the PG:PL ratio obtained herein taken together with previous reports indicate that $P G$ is converted to PL more efficiently in ovine milk, and thus, species differences do occur.

The sum of PL+PG may indicate the amount of PG, $\mathrm{PL}$, or both, entering milk from the blood. This is because PG is not expressed in the mammary gland (Politis, 1996). The sum of PL+PG is lower in the lowproducing Boutsiko breed compared with the high-producing Chios breed. This difference cannot be attributed to differences in milk yield. The inclusion of daily milk yield as an overall or nested (within breed) covariate in the statistical model did not affect the results. Furthermore, the difference cannot be attributed to a dilution effect because the breed with the greatest milk production was also the breed with the greatest sum of PG+PL. Thus, there is presumably more influx of PG or PL in the Chios breed compared with the Boutsiko breed.

The second finding emerging from the present study is that there is no relationship between increased amounts of PL and milk yield in the 3 Greek dairy sheep breeds. This conclusion is supported by 3 observations. First, the Chios breed produced $108 \%$ more milk than the Boutsiko, and $49 \%$ more than the synthetic breed. Yet, there were no differences in PL activity between the 3 breeds. Second, none of the partial correlation coefficients between PL, PG, and PA activities and milk yield were significant $(P>0.05)$. Third, the lowest PL activity in all breeds was detected during late lactation, which coincides with the lowest milk yields for all 3 Greek sheep breeds. Thus, PL is not a marker for gradual involution in the 3 Greek dairy sheep breeds studied. These data are in contrast to those previously ob- 
Table 4. Least squares means ( $\pm \mathrm{SEM})$ of plasmin $(\mathrm{PL})$, plasminogen (PG), plasminogen activator (PA), and the sum of PL+PG activities, along with the medians and the interquartile ranges of the PG:PL ratio as affected by the health status of the udder ${ }^{1}$

\begin{tabular}{lcc}
\hline & \multicolumn{2}{c}{$\mathrm{SCC}$, cells/mL } \\
\cline { 2 - 3 } Item & $<300,000$ & $>300,000$ \\
\hline Observations, $\mathrm{n}$ & 326 & 53 \\
$\mathrm{PL}, \mathrm{U} / \mathrm{mL}^{2}$ & $6.43 \pm 0.15^{\mathrm{a}}$ & $8.56 \pm 0.36^{\mathrm{b}}$ \\
$\mathrm{PG}, \mathrm{U} / \mathrm{mL}$ & $9.08 \pm 0.18^{\mathrm{a}}$ & $7.43 \pm 0.41^{\mathrm{b}}$ \\
$\mathrm{PA}, \mathrm{U} / \mathrm{mL}$ & $8.40 \pm 0.33^{\mathrm{a}}$ & $13.40 \pm 0.53^{\mathrm{b}}$ \\
$\mathrm{PL}+\mathrm{PG}, \mathrm{U} / \mathrm{mL}$ & $1.4^{\mathrm{a}}$ & $11.60 \pm 0.49^{\mathrm{b}}$ \\
PG:PL ratio & 1.14 & $0.83^{\mathrm{b}}$ \\
Median & Interquartile range & 0.15 \\
\hline
\end{tabular}

${ }^{\mathrm{a}, \mathrm{b}}$ Means within the same row followed by different letters differ at $P<0.05$.

${ }^{1}$ All values are from the main effects fitted in the model and they are square-root transformed.

${ }^{2} \mathrm{U}=$ activity unit; 1 unit is the amount of $\mathrm{PL}$ that produces a change in absorbance of 0.1 at $405 \mathrm{~nm}$ in $60 \mathrm{~min}$.

tained by Politis et al. (1989, 1990), who reported strong negative correlations between PL activity and milk yield at late lactation (declining phase) in the dairy cow. Thus, species differences occur between cows and ewes.

The third finding emerging from the present study is that the PL-PG system is affected by the stage of lactation. The lowest PL, PG, and PA activities were detected during late lactation (mo 5 and 6 of lactation). These results have striking similarity to those of Albenzio et al. (2004), who reported that PL activity was greatest in early and lowest in late lactation milk obtained from Comisana ewes. In contrast, Bianchi et al. (2004) reported increased PL and PA activities in late lactation milk obtained from Sardinian ewes. Apparently, differences occur between sheep breeds.

It is interesting to note that the PG:PL ratio was lower in late lactation milk compared with early and mid lactation milk. Plasminogen, therefore, is converted to PL more efficiently in late lactation milk. The more efficient conversion of PG to PL in late lactation milk is not consistent with the PA values, which were greatest during early and lowest during late lactation (Table 3). One should expect, therefore, the highest rate of conversion in early lactation milk, not in late lactation milk. The sum of $\mathrm{PG}+\mathrm{PL}$ can provide some insight regarding this unusual observation (i.e., low PG:PL ratio and low PA activity in late lactation milk). The sum of $\mathrm{PG}+\mathrm{PL}$ and the PA values were lower in late lactation than in early lactation milk, indicative of reduced influx from blood to milk. This is not consistent with results of others who established the weakening of the tight junctions of the mammary gland that occurs in late lactation in cows (Stelwagen et al., 1994; LacyHulbert et al., 1999) and sheep (Albenzio et al., 2004).
We favor the hypothesis that the influx of PL inhibitors is increased during late lactation leading to underestimation of all values (PL, PG, and PA). All 3 determinations share the same final step. In the PG assay, $\mathrm{PG}$ is converted to PL by the addition of urokinase. In the PA assay, endogenous PA converts exogenous PG to PL. The PL in all 3 assays, therefore, hydrolyzes the chromogenic substrate Val-Leu-Lys-p-nitroanilide. It is apparent that the presence of high amounts of PL inhibitors will influence all 3 determinations and will lead to underestimation of all 3 values. In a similar fashion, Albenzio et al. (2004) reported that entrance of PL inhibitors in late lactation was the most logical explanation for the low PL and PG values they observed in their study. The activities of PL inhibitors, however, were not determined in the present study.

The PL-PG system is affected by the health status of the udder. Plasmin, PG, and PA activities were increased in the high-SCC group. Furthermore, the PG:PL ratio was lower in the high-SCC group, which indicates faster conversion of PG to PL. It is interesting to note that the sum of PL+PG was greater in the highSCC group. These data taken together suggest that 2 mechanisms may be working in parallel. First, increased influx of blood proteins occurs in the high-SCC group, which is consistent with high PL+PG and PA activities in this group. Second, increased conversion of PG to PL occurs in the high-SCC group, which is consistent with higher PA values in this group. Data obtained from the present study are similar to those of Leitner et al. (2004), who investigated differences in the PL-PG system in ovine milk obtained from infected and noninfected glands from Assaf dairy sheep. They reported greater PL and PA values and lower PG values in the infected gland, indicating that the main mechanism is faster conversion of PG to PL in the infected glands. Bianchi et al. (2004) reported greater PL and lower PA activities in the infected compared with the noninfected glands of Sardinian ewes. Albenzio et al. (2004) reported greater PL values in the high-SCC group compared with the low-SCC group. Their definition of high-SCC milk, however, was milk with $>1$ million cells $/ \mathrm{mL}$. Differences between the studies cannot be explained at this moment. Factors that could have contributed to this phenomenon might be differences between breeds and differences in the methodology used.

In conclusion, the PL-PG system was affected by breed, stage of lactation, and the health status of the udder. Accelerated conversion of PG to PL occurred during late lactation and in the high-SCC group $(>300,000 / \mathrm{mL})$. No relationship existed between PL activity and daily milk yield in the 3 Greek dairy sheep breeds. The low PL values at late lactation, which coin- 
cided with low milk yields, suggested that PL is not a marker for gradual involution in the 3 Greek dairy sheep breeds.

\section{REFERENCES}

Albenzio, M., M. Caroprese, A. Santillo, R. Marino, A. Muscio, and A. Sevi. 2005. Proteolytic patterns and plasmin activity in ewes' milk as affected by somatic cell count and stage of lactation. J. Dairy Res. 72:86-92.

Albenzio, M., M. Caroprese, A. Santillo, R. Marino, L. Taibi, and A. Sevi. 2004. Effects of somatic cell count and stage of lactation on the plasmin activity and cheese-making properties of ewe milk. J. Dairy Sci. 87:533-542.

AOAC. 1980. Official Methods of Analysis. 13th ed. Association of Official Analytical Chemists, Arlington, VA.

Baldi, A., G. Savoini, F. Cheli, F. Fantuz, E. Senatore, L. Bertocchi, and I. Politis. 1996. Changes in plasmin-plasminogen-plasminogen activator system in milk from Italian Friesian Herds. Int. Dairy J. 6:1045-1053.

Bianchi, L., A. Bolla, E. Budelli, A. Caroli, C. Casoli, M. Pauselli, and E. Duranti. 2004. Effect of udder health status and lactation phase on the characteristics of Sardinian ewe milk. J. Dairy Sci. 87:2401-2408.

Gilmore, J., J. H. White, B. Zavizion, and I. Politis. 1995. Effect of stage of lactation and somatic cell count on plasminogen activator activity in bovine milk. J. Dairy Res. 62:141-145.

Grubbs, F. 1969. Procedures for detecting outlying observations in samples. Technometrics 11:1-21.

Hatziminaoglou, J., N. P. Zervas, and J. G. Boyazoglu. 1990. Prolific dairy sheep breeds in Greece. Options Méditerraneennes Ser. A, 12:25-30.
Kominakis, A., E. Rogdakis, and K. Koutsotolis. 1998. Genetic parameters for milk yield and litter size in Boutsiko dairy sheep. Can. J. Anim. Sci. 78:525-532.

Lacy-Hulbert, S. J., M. W. Woolford, G. D. Nicholas, C. G. Prosser, and K. Stelwagen. 1999. Effect of milking frequency and pasture intake on milk yield and composition of late lactation cows. J. Dairy Sci. 82:1232-1239.

Leitner, G., M. Chaffer, A. Shamay, F. Shapiro, U. Merin, E. Ezra, A. Saran, and N. Silanikove. 2004. Changes in milk composition as affected by subclinical mastitis in sheep. J. Dairy Sci. 87:46-52.

Ploumi, K., S. Belibasaki, and G. Triantaphyllidis. 1998. Some factors affecting daily milk yield and composition in a flock of Chios ewes. Small Rumin. Res. 28:89-92.

Politis, I. 1996. Plasminogen activator system: Implication for mammary cell growth and involution. J. Dairy Sci. 79:1097-1107.

Politis, I., E. Block, and J. D. Turner. 1990. Effect of somatotropin on the plasminogen and plasmin system in the mammary gland: Proposed mechanism of action for somatotropin on the mammary gland. J. Dairy Sci. 73:1494-1499.

Politis, I., E. Lachance, E. Block, and J. D. Turner. 1989. Plasmin and plasminogen in bovine milk: A relationship with involution. J. Dairy Sci. 72:900-906.

Politis, I., and K. F. Ng Kwai Hang. 1989. Environmental factors affecting plasmin activity in milk. J. Dairy Sci. 72:1713-1718.

SAS Institute. 2004. SAS/STAT Software. Version 9.0 for Windows. SAS Inst. Inc., Cary, NC.

Simos, E. N., E. M. Nikolaou, and P. E. Zoiopoulos. 1996. Yield, composition and certain physicochemical characteristics of milk of the Epirus mountain sheep breed. Small Rumin. Res. 20:67-74.

Srinivasan, M., and J. A. Lucey. 2002. Effects of added plasmin on the formation and rheological properties of rennet-induced skim milk gels. J. Dairy Sci. 85:1070-1078.

Stelwagen, K., I. Politis, J. H. White, B. Zavizion, C. G. Prosser, S. R. Davis, and V. C. Farr. 1994. Effect of milking frequency and somatotropin on the activity of plasminogen activator, plasminogen, and plasmin in bovine milk. J. Dairy Sci. 77:3577-3583. 